of home, leisure, traffic and work injuries estimated by surveybased and registry based methods among adults in Luxembourg. Methods Survey based data on 1529 residents aged 25-64, were collected during 2013/2014 in the frame of the European Health Examination Survey (EHES). Luxembourgish ED registry based data supplied to the European Injury Data Base (IDB) for the period 2013-2014 were used for the comparison. Both IDB and EHES are now part of the BRIDGE-Health (BRidging Information and Data Generation for Evidence-based Health Policy and Research) development.

Results The estimated incidence rate of all the selected injuries from registry-based data was $8.4 \%$ in 2013 and $8.3 \%$ in 2014. From survey based data the incidence of; injuries treated in hospital (CI: 95\%) was $8.8 \%(7.7 \% ; 10.4 \%)$, treated outside the hospital was $3.6 \%(2.8 \%: 4.7 \%)$ and not medically treated was 2.7\% (2.0\%: 3.7\%).

Conclusions Both survey and registry based data are concordant in estimating ED treated injury incidence among 25-64 years old in Luxembourg.

\section{HOSPITAL REGISTRATIONS AND HEALTH SURVEY DATA - DO THEY AGREE?}

${ }^{1}$ Bjarne Larsen, ${ }^{2}$ Huib Valkenberg, ${ }^{3,4}$ Ronan A Lyons, ${ }^{3}$ Samantha Turner, ${ }^{5}$ Wim Rogmans, ${ }^{6}$ Rupert Kisser, ${ }^{7}$ Gabriele Ellsässer, ${ }^{8}$ Dritan Bejko, ${ }^{9}$ Monica Steiner. ${ }^{1}$ National Institute of Public Health, University of Southern Denmark; ${ }^{2}$ Consumer Safety Institute, The Netherlands; ${ }^{3}$ Farr Institute Swansea University, Medical School, UK; ${ }^{4}$ Public Health Wales NHS Trust, UK;

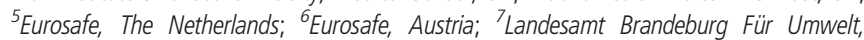
Gesundheit Und Verbraucherschutz, Germany; ${ }^{8}$ Centre d'Etudes en Santé Publique, Luxembourg; ${ }^{9}$ Austrian Road Safety Board, Austria

\subsection{6/injuryprev-2016-042156.224}

Background In many countries health interview survey data are used for indicators for injury incidence. However, the validity of self-reported injury incidence may be questioned due to e.g. recall bias and low response rate in groups at high injury risk. In the first European Health Interview Survey the incidence of home and leisure injuries varied as much as from $1.3 \%$ to $8.2 \%$. The purpose of the present study is to compare survey response and hospital registration at the individual level with focus on reporting bias.

Methods This study was carried out using the Danish health interview survey data with information on injury the past year and the treatment. These data were linked at the individual level to the hospital registration of both in- and outpatient data for the period up to two year before the interview, for all hospitals in Denmark.

Results In total 368 reported injuries being hospital treated as outpatient, of these 234 were actually hospital treated within the last 12 months (64\%). Ninety-six reported being admitted to hospital, of these 51 were actually admitted the past year (53\%) and 59 the past two years (61\%). Conversely, only about half of the hospital treated injuries were reported in the survey.

Conclusions There is considerable disagreement at the individual level between self-reported hospital treated injuries and actual hospital treatment. Hospital admissions in particular seem to be over reported.

\section{BUNK BEDS PLACE OF DANGER?}

${ }^{1}$ Gabriele Ellsäßer, ${ }^{1}$ Frank Gries, ${ }^{2}$ Tania Vandenberghe. ${ }^{1}$ Department of Health within the State Office of Environment, Health and Consumer Protection, Brandenburg/Germany; ${ }^{2} A N E C$, the European Consumer Voice in Standardisation, Belgium

\subsection{6/injuryprev-2016-042156.225}

Background The European standard for bunk beds, EN 747-1, was amended in 2015 to introduce the need for manufacturers to mark bunk beds with either a warning text or a pictogram indicating the beds are not suitable for children $<6$ ys. Whilst applauding the amendment to this standard, we do however need to continue analysing the injury event in order to identify high risk groups, critical circumstances. Since 2008 the full Injury Database (FDS) has been implemented in three main German hospitals with paediatric wards reporting to the Brandenburg Department of Health. The FDS contains product related injuries, the doctor's narrative and injuries with bunk beds were specifically identified.

Methods Monitoring of injured patients $<18$ ys admitted to hospital (either at emergency department or paediatric ward) based on the European IDB standard during 2008-2014. Analysis of 10,332 injury cases in under 10 -year-olds. Bunk bed injuries were counted when a bunk bed was mentioned as a "trigger" or "causing" factor $(\mathrm{n}=170)$.

Results Products were involved in 7,730 (75\%) injuries in under 10 -year-olds. Specifically bunk beds were the $7^{\text {th }}$ most frequent product related cause of injuries in the $<$ six-year-olds and the $4^{\text {th }}$ in the 2-to3-year-olds. $133(78 \%)$ of all bunk bed injuries occurred in the $<6$-year-olds. The most frequent accident events were \#1 falling out of the upper bunk bed, \#2falls from bunk bed steps and \#3 falls from bunk bed related furniture (e.g. slides). 100 (58\%) of these injuries demanded hospital admission, of which 75 serious head injuries (ICD-10 S01 - S06) and 18 suffered a second injury.

Conclusions When buying bunk beds, parents seem to be unaware of the danger for very young children. The amended European standard is an important step forward, but parental care is equally important. A parental education campaign would be valuable. Last but not least, enforcement of the new standard is crucial as well.

\section{USING LONG BONE FRACTURES AS AN INJURY INCIDENCE INDICATOR IN EUROPE}

${ }^{1,2}$ Ronan A Lyons, ${ }^{1}$ Samantha Turner, ${ }^{3}$ Bjarne Larsen, ${ }^{4}$ Wim Rogmans, ${ }^{5}$ Robert Bauer, ${ }^{6}$ Gabrielle Ellsessaer, ${ }^{7}$ Huib Valkenberg, ${ }^{8}$ Dritan Bejko. ${ }^{1}$ Farr Institute Swansea University, Medical School, UK; ${ }^{2}$ Public Health Wales NHS Trust, UK; ${ }^{3}$ National Institute of Public Health, Denmark; ${ }^{4}$ Eurosafe, The Netherlands; ${ }^{5}$ Austrian Road Safety Board, Austria; ${ }^{6}$ Landesamt Brandenburg Für Umwelt, Gesundheit Und Verbraucherschutz, Germany; ${ }^{7}$ Consumer Safety Institute, The Netherlands; ${ }^{8}$ Luxembourg Institute of Health, Luxembourg

\subsection{6/injuryprev-2016-042156.226}

Background It is important to select robust injury indicators for international comparisons and evaluation of preventive interventions. Emergency department data provide the best opportunity for robust indicators with the greatest utility. Previous analyses have suggested that long bone fracture (LBF) incidence should be a robust population indicator for use by emergency department surveillance systems (Lyons et al. 2006 \& Polinder et al. 2008). The purpose of this study was to compare between country 